\title{
$\angle S$ Research Square \\ Highly palatable and hypercaloric chronic intake of food and soft drink leads to disruption in the normal dietary pattern in rats
}

\author{
Martine Elisabeth Kienzle Hagen ( $\nabla$ martine.hagen@ufrgs.br) \\ Universidade Federal do Rio Grande do Sul https://orcid.org/0000-0002-3838-3866 \\ Isabel Cristina Macedo \\ UNIPAMPA: Universidade Federal do Pampa \\ Rutiane Ullmann Thoen \\ Universidade Federal do Rio Grande do Sul \\ Rafael Oliveira Fernandes \\ Universidade Federal do Rio Grande do Sul \\ Jeferson Ferraz Goularte \\ Universidade Federal do Rio Grande do Sul \\ Gilberto Luiz Sanvitto \\ FEEVALE University: Universidade FEEVALE \\ Iraci L.S. Torres \\ Universidade Federal do Rio Grande do Sul
}

\section{Research Article}

Keywords: soft drink, food intake, eating behavior, cafeteria diet, obesity, ultra-processed food

Posted Date: April 1st, 2021

DOI: https://doi.org/10.21203/rs.3.rs-367502/v1

License: (c) (i) This work is licensed under a Creative Commons Attribution 4.0 International License. Read Full License 


\section{Abstract}

Ultra-processed food consumption, which is highly palatable, rich in fat, sugar, and salt causes uncontrolled food intake and has contributed to a sharp increase in obesity worldwide. This study evaluated the effects of soft drink and/or ultra-processed food intake on eating behavior and metabolic parameters in rats fed with a cafeteria diet. Male Wistar rats were divided into six groups. 1) CON: standard chow and water; 2) CD: cafeteria diet, standard chow, and water; 3) CS: caloric soft drink, standard chow, and water; 4) NCS: non-caloric soft drink, standard chow, and water; 5) CD + CS: cafeteria diet, caloric soft drink, standard chow, and water; and 6) CD + NCS: cafeteria diet, non-caloric soft drink, standard chow, and water. The cafeteria diet intake resulted in higher energy consumption (30\% increase on average), a $450 \%$ increase in lipid consumption, and a $50 \%$ reduction in protein intake, which contributed to a $60 \%$ increase in body weight relative to the controls. This diet increased the metabolic risk, as observed in the Homeostasis Model Assessment changes in the CD groups. The CD + NCS group presented a lower liposomatic index, which may be related to the lower insulinogenic effect of caffeine contained in the soda, and 17\% carbohydrate reduction compared to the $\mathrm{CD}+\mathrm{CS}$ group. This result suggests that caffeine consumption in noncaloric soda may help prevent obesity associated with the sucrose's absence. However, it is necessary to compare the effects of the sugary drink intake with those of the artificially sweetened consumption, caffeine-free drinks associated with a cafeteria diet.

No Level of evidence: animal study.

\section{Introduction}

Consumption of soft drinks and highly palatable food is changing eating habits and impairing food control. These foods, also known as ultra-processed foods, contain a low nutritional value and because they are very palatable, are consumed excessively, resulting in high-calorie intake in the form of carbohydrates and fats, and reduced fiber, mineral, and vitamin consumption. Those who consume large amounts of ultra-processed food consume an insufficient quantity of fruits and vegetables, which contributes to the increase in obesity worldwide [1-5]. Obesity is a multifactorial disease, but it undoubtedly causes excessive consumption of ultra-processed foods, thus resulting in a marked increase in energy consumption and contributing decisively to the development of this disease [6-8]. It should be noted that overweight and obesity are the main risk factors for several chronic non-communicable diseases, including type 2 diabetes mellitus (DM2), heart disease, hypertension, asthma, arthritis, metabolic syndrome, and various types of cancers (World Health Organization, 2018). Unfortunately, overweight and obesity are not just a concern in developed countries, but also in developing countries, especially in urban environments. According to the World Health Organization, in 2016, more than 1.9 billion adults were diagnosed as overweight, of which 650 million were obese (World Health Organization, 2017).

The act of eating has a complex involvement of pleasure and reward with motivations and behaviors involving several neural systems [9-11]. Food dependency has been described in the literature, despite not being formally recognized by the Diagnostic and Statistical Manual of Mental Disorders-5 [12]. However, some studies have indicated changes in the brain reward circuit induced by excessive consumption of highly palatable foods, like those observed in substance use disorder. Regarding differences between foods, it has been proposed that addiction is particularly associated with ultra-processed foods [13]. They have a high glycemic load (because they are rich in sugar and/or other refined carbohydrates), rich in fat, or both. The hyper-palatability of these foods results from the sweet, salty, or umami flavor, which is associated with high caloric density [14]. 
Natural foods rarely have an excessive amount of sugar and fat at the same time, and are usually either high in carbohydrates (e.g., fruits and honey), or high in fat (nuts and avocado), but ultra-processed foods have artificially high amounts of both (e.g., cake, pizza, chocolate), and are readily available [15]. Excessive sugar intake does not seem to affect body weight but combining the intake of sweets with fat results in increased body weight [16]. Fat can be the nutrient that leads to excess weight, and the sweet taste can be the main contributor to the production of addictive behavior, including withdrawal syndrome [17].

The cafeteria diet has been widely used as a model for inducing obesity in laboratory animals because of its great similarity with genesis and metabolic responses due to obesity in humans [18-20]. In a previous study [21], the supply of a balanced diet and caloric or non-caloric soft drinks did not cause changes in total energy intake, body weight, and intra-abdominal and perigonadal fat deposition in rats during the 17 weeks of exposure. However, caloric soft drink intake decreased the consumption of standard chow, with a consequent reduction in consumption of nutrients such as vitamins and minerals. Interestingly, the non-caloric soft drink intake did not influence food consumption. Both caloric and non-caloric soft drinks increased the total liquid consumption with a strong decrease in water consumption. These results motivated the investigation into the feeding behavior of the animals in the face of exposure to caloric and non-caloric soft drinks and the offer of highly palatable solid foods. Due to the lack of evidence on the effects of the association of caloric and non-caloric soft drink intake with an industrialized and highly palatable diet, this study evaluated the effects of soft drink and/or ultra-processed food intake on the eating behavior and metabolic parameters in rats that were fed a cafeteria diet.

\section{Methods}

\subsection{Experimental Procedures}

The sample size was calculated using WINPEPI v. 11.1 software. Significance was set at 0.05 with $80 \%$ power, using the Milagro et al. study as a reference [22]. A sample of 10 animals per group was set to account for foreseeable failure to complete the protocol. A total of sixty, 2 months old, male Wistar rats were provided by the Laboratory of Animal Reproduction and Experimentation of the Universidade Federal do Rio Grande do Sul. The rats were acclimatized to their environment for one week before the start of the experiment. The experiments and procedures were approved by the Institutional Animal Care and Use Committee (protocol no. 13-0136), were compliant with Brazilian guidelines involving the use of animals in research (Federal Law 11,794/2008) and were performed in accordance with the International Guidelines for Animal Welfare. The minimum number of animals required to produce reliable scientific data was used, and efforts were made to minimize suffering and external sources of pain and discomfort.

All animals were kept in polypropylene boxes ( 2 animals/box) in a 12-hour dark-light cycle, with humidity between $70 \%$ and $80 \%$, a temperature equal to $22 \pm 2{ }^{\circ} \mathrm{C}$, and were provided food and beverage ad libitum for 12 weeks. The animals were randomized according to body weight and phase angle determined by electric bioimpedance and separated into six experimental groups: the control group $(\mathrm{CON}, \mathrm{n}=10)$ received standard chow and water; the caloric soft drink group (CS, $n=10$ ) received standard chow, water, and a caloric soft drink; the non-caloric soft drink group (NCS, $n=10)$ received standard chow, water, and a non-caloric soft drink; the cafeteria diet group $(C D, n=10)$ received standard chow, water, and cafeteria diet; the cafeteria diet with caloric soft drink group (CD+CS, $n=10)$ received standard chow, water, cafeteria diet, and a caloric soft drink; and the cafeteria diet with a non-caloric soft drink $(C D+N C S, n=10)$ received standard chow, water, cafeteria diet, and a non-caloric soft drink. 
The chow used was Nuvilab CR-1 rat and mice chow, with an energy density of $12.34(\mathrm{~kJ} / \mathrm{g}), 2.7 \mathrm{mg} / \mathrm{g}$ of sodium, and a macronutrient proportion of $55 \%$ carbohydrates, $22 \%$ protein, and $4.5 \%$ lipids. Soft drinks were purchased from local shops, and nutritional values were obtained from the manufacturer's website (Coca-Cola ${ }^{\circledR}$ ). Nutritional composition of Regular Coca-cola ${ }^{\circledR}: 1.78 \mathrm{~kJ} / \mathrm{mL} ; 0.11 \mathrm{~g} / \mathrm{mL}$ carbohydrate; $0.05 \mathrm{mg} / \mathrm{mL} \mathrm{Na} ; 0.1 \mathrm{mg} / \mathrm{mL}$ caffeine. Nutritional composition of Zero Coca-cola ${ }^{\circledR}: 0.0 \mathrm{~kJ} / \mathrm{mL} ; 0.0$ carbohydrate; $0.28 \mathrm{mg} / \mathrm{mL} \mathrm{Na;} 0.1 \mathrm{mg} / \mathrm{mL}$ caffeine. The cafeteria diet was based on previous studies $[18,19,23]$. The foods included in the cafeteria diet were sandwich cookies, wafers, sausages, chips, and condensed milk. Both the standard chow and the cafeteria diet were replaced daily with fresh food. The animals receiving the cafeteria diet also had access to standard chow and water. The nutritional composition of the diets is shown in Table 1. Controls of animal food and drink intakes were performed simultaneously by the staff daily. Daily food and drink consumptions were calculated by subtracting the amount offered from leftovers after $24 \mathrm{~h}$. This value was summed up and divided by the number of animals in the box, resulting in individual intake estimates, and then divided by the average weight of the animals.

\subsection{Bioelectrical Impedance Analysis}

To measure the total body resistance $(\mathrm{R})$ and total body reactance $(\mathrm{Xc})$, a phase-sensitive tetrapolar impedance analyzer (Biodynamics BIA 450E) was used with hypodermic needles as electrodes. The rats were anesthetized and placed in a prone position on a non-conductive surface to eliminate interference from electrical induction. On the midline, source electrode 1 was placed at the anterior edge of the orbit, and source electrode 2 was placed $4 \mathrm{~cm}$ from the base of the tail. Detector electrode 1 was placed at the anterior opening of the ear, and detector electrode 2 was placed in the middle of the rat pelvis [24]. The analysis was performed in two phases: the initial phase (Time 1) and the final phase (Time 2).

\subsection{Body Composition and Blood Collection}

Bodyweight was assessed weekly at baseline and the end of the experiment. After 12 weeks, the animals were euthanized by decapitation after a 12-hour fasting period. Blood was collected in test tubes and allowed to settle for $30 \mathrm{~min}$ before centrifugation. It was subsequently separated into aliquots and stored at $-80^{\circ} \mathrm{C}$ until the completion of serum analysis. To obtain the total weight gain of the animals, the weight at the start of treatment was subtracted from the last recorded weight before euthanasia. The intra-abdominal adipose tissue and perigonadal adipose tissue were removed and weighed jointly in a semi-analytical balance (Shimadzu BL3200). The liposomatic index (LI) was calculated by dividing the weight of visceral adipose tissue by the bodyweight of the animals at the end of 12 weeks. Visceral fat was obtained by dissecting the fat of the animals after euthanasia.

\subsection{Serum Levels}

Commercial kits were used to determine serum glucose concentration (Glucose PAP Liquiform, Labtest, Brazil) and lipid profile (Cholesterol Liquiform, HDL-cholesterol, and Triglycerides Liquiform, Labtest, Brazil). Serum insulin and leptin levels were determined by enzyme-linked immunosorbent assay (ELISA) using reagents specific for rats (Millipore), with a detection sensitivity of $0.2 \mathrm{ng} / \mathrm{mL}$. The homeostasis model assessment of insulin resistance (HOMA-IR) was used to calculate approximate insulin resistance (fasting glucose $[\mathrm{mg} / \mathrm{dL}] \times$ fasting insulin $[\mathrm{mIU} / \mathrm{mL}] / 2430)[25]$.

\subsection{Statistical Analysis}

The distribution of variables was analyzed using the Shapiro-Wilk test, and values were expressed as the mean and standard error. The effects of each treatment on the intake of chow, nutrients, energy, water, total liquid, body weight, 
adipose tissue weight, glucose, insulin, leptin, total cholesterol, HDL-cholesterol, triglycerides, and HOMA-IR were analyzed at the end of the treatment by one-way ANOVA with Tukey's post hoc test. Student's t-test was used to analyze the energy and carbohydrate intake of the two groups receiving caloric soft drinks at the end of the experiment. All analyses were performed using SPSS ${ }$, version 18 , with $p<0.05$ being considered statistically significant.

\section{Results}

\subsection{Food, Beverages, and Energy Intake}

The intakes of standard chow and cafeteria diet are represented as the daily averages in grams per animal (Figure 1, panels $A-C)$. The intakes of water, soft drink, and total liquids are represented as the daily averages in milliliters per animal (Figure 1, panels D-F). There was a significant difference in chow intake between the groups $[F(5,54)=$ $356,283 ; p<0.001]$. In the non-cafeteria groups, only the CS group showed a significant reduction in chow intake ( $p<0.001)$ when compared to the CON group. The groups that received cafeteria diet $(C D, C D+C S$, and CD+NCS) showed decreased chow intake when compared to their respective non-cafeteria groups $(p<0.001$ for all). Total solid food intake was similar among groups, except for the CS group, which presented a significant reduction in solid intake when compared to all other groups $(p<0.001)$. There was a difference in water intake between the groups $[F(5$, $54)=39,408 ; p<0.0001$ ]. All groups showed decreased water intake when compared to the CON group ( $p<0.001$ for all). The CS and CD+CS groups presented similar water intake; however, NCS drank significantly more water than $\mathrm{CD}+\mathrm{NCS}(p=0.003)$. The consumption of caloric soft drinks was almost twice as high in the presence of standard chow when compared with $\mathrm{CD}+\mathrm{CS}$, as well as other groups that received caloric soft drinks.

There was a significant difference in total energy intake, represented by the sum of solid and liquid energy between groups $[F(5,54)=18,793 ; p<0.0001]$ (Figure 1, panels $G-1$ ). The total energy intake was similar in the standard chow groups, as well as in the cafeteria diet groups. However, all cafeteria diet groups consumed more energy than the standard chow groups $(p<0.001)$, except for the CS group that consumed total energy like the cafeteria group. Comparing only solid energy intake, the CS group consumed less energy compared to all other groups ( $p<0.001$ for all). CON and NCS consumed similar solid energy intake and cafeteria groups consumed more than the standard chow groups $(p<0.001$ for all).

\subsection{Standard Chow and Experimental Diets Content}

The intakes of the carbohydrate, protein, and lipid dietary contents of cafeteria diet or soft drinks were expressed in daily average grams per animal, while the sodium and caffeine contents were expressed as daily mean in milligrams per animal (Table 2). There was a significant difference between the groups in total carbohydrate intake $[F(5,54)=18,298 ; p<0.0001]$. In addition, the CS group had reduced carbohydrate intake in solid foods (standard chow), and increased carbohydrate intake in caloric soft drinks as compared to CON $(p<0.001)$ and CD+CS $(p<0.001)$ groups. The NCS group consumed fewer carbohydrates in total than the CS group $(p<0.001)$, but similar to the other groups. There was a significant difference in protein intake between the groups $[F(5,54)=99,693$; $p<0.0001]$. The CS group consumed less protein than the CON $(p<0.001)$ and NCS groups $(p<0.001)$. Cafeteria diet intake led to a reduction in protein consumption in all groups when compared to the controls $(p<0.0001)$. There was a significant difference in lipid intake between the groups $[F(5,54)=206,026 ; p<0.0001]$. Cafeteria diet groups (CD, $\mathrm{CD}+\mathrm{CS}$, and $\mathrm{CD}+\mathrm{NCS}$ ) consumed more lipids than their controls ( $p<0.0001 \mathrm{for}$ all). No differences were observed among the cafeteria groups $(p>0.05)$. There was a significant difference in total sodium intake between the groups $[F(5,54)=59,019 ; p<0.001]$. The total sodium intake in the cafeteria diet group was significantly higher than that in 
the CON $(p<0.0001), \operatorname{CS}(p<0.001)$, and NCS ( $p<0.001)$ groups. There was a significant difference in caffeine intake among the groups that received a soft drink $[F(3 ; 36)=23,750 ; p<0.0001]$. The CS group showed an increase in caffeine intake compared to the CD + CS $(p<0.001)$, NCS $(p<0.001)$, and CD+NCS $(p<0.001)$ groups. In contrast, the NCS group did not differ from the cafeteria group CD+NCS $(p>0.05)$.

\subsection{Body Weight Gain and Liposomal Index}

Weight gain is expressed in grams (Figure 2, panel A). The LI was calculated by dividing the weight of visceral adipose tissue by the bodyweight of the animals at the end of treatment (Figure 2, panel B). The groups that received the cafeteria diet showed a significant increase in weight in relation to their controls $[F(5 ; 54)=12,556$; $p<0.0001]$. The CD group showed increased weight gain compared to the CON group $(p<0001), \mathrm{CD}+\mathrm{CS}$ compared to the CS group ( $p<0.004)$, and CD+NCS compared to the NCS group ( $p<0.03)$. Similar differences were observed in LI [CD versus CON $(p<0.0001)$; CD+CS versus CS ( $p<0.0001)$; however, $\mathrm{CD}+\mathrm{NCS}$ did not differ from the control NCS $(p<0.07)]$. Moreover, the $\mathrm{CD}+\mathrm{NCS}$ group showed a decrease in $\mathrm{LI}$ compared to $\mathrm{CD}(p<0.007)$ and $\mathrm{CD}+\mathrm{CS}$ groups $(p<0.008)$; LI from NCS was not statistically different from the CD+NCS group.

\subsection{Biochemical Markers}

Serum biochemical levels at the end of treatment are shown in Table 3. Fasting glucose, total cholesterol, HDL cholesterol, and non-HDL cholesterol were similar for all groups at the end of treatment $(p>0.05)$. There was a significant difference in HOMA-IR between the groups $[F(5,54)=10.505 ; p<0.0001]$. The cafeteria groups (CD and $\mathrm{CD}+\mathrm{CS})$ showed an increase in HOMA-IR as compared to CON groups [CD $(p<0.05)$ and $\mathrm{CD}+\mathrm{CS}(p<0.0001)$, respectively], but not in the $\mathrm{CD}+\mathrm{NCS}$ group. A significant difference in triglyceride levels was identified between the groups $[F(5,54)=7.371 ; p<0.0001]$. The $C D$ and $C D+C S$ groups presented an increase in triglyceride levels as compared to the CON group ( $p<0.001$ and $p<0.008)$, CS group $(p<0.001$ and $P<0.01)$, and NCS group $(p<0.002$ and $p<0.01)$, without differences between the CD + NCS group and the control and cafeteria groups. Similar results were observed in insulin levels between the groups $[F(5 ; 54)=10.201 ; p<0.0001]$. The CD and CD $+C S$ groups showed a significant increase in insulin levels in relation to their controls [CON $(p<0.008)$ and $C D+C S(p<0.0001)$, respectively], except in the CD + NCS group. There was a significant difference in leptin levels between the groups $[F(5,54)=$ 8.805; $p<0.000]$. The CD group showed an increase in leptin levels as compared to the CON, CS, and NCS groups $(p<0.004, p<0.002$, and $p<0.005$, respectively). The CD+CS group also showed an increase in leptin levels as compared to the CON $(p<0.001)$, CS $(p<0.0001)$, and NCS $(p<0.001)$ groups. No difference was observed in the $\mathrm{CD}+\mathrm{NCS}$ group as compared to the control and the other cafeteria groups $(p>0.05)$.

\section{Discussion}

The present study demonstrates that experimental animals exposed to caloric soft drinks and/or ultra-processed food consumption (cafeteria diet) developed hyperphagia and significant changes in normal feeding patterns. These affirmations are made based on the results showing that exposure to caloric soft drinks decreases chow intake by $30 \%$. This decrease in the consumption of standard chow was even more drastic when a caloric soft drink was offered in association with the cafeteria diet, leading to a drastic reduction (90\%) in the consumption of standard feed. The caloric soft drink consumption was greater than the non-caloric soft drink intake regardless of its exposure alone (68\% increase) or in conjunction with a cafeteria diet (38\% increase). The chow intake of animals exposed to non-caloric soft drinks did not decrease compared to the control group, reflecting lower total energy consumption in non-caloric soft drinks compared to caloric soft drinks. However, the cafeteria diet was responsible for an increase in energy intake from solid foods. It was 32\% more in CD than in CON, $24 \%$ more in CD + CS than in 
CS, and $34 \%$ more in CD + NCS than in NCS. These results demonstrated that the animals replaced the standard chow with caloric soft drinks and/or ultra-processed foods. Over the past few years, this concern has grown and motivated other studies that have shown similar results [26-29].

The higher caloric soft drink intake of the CS group resulted in an increase of $33 \%$ in carbohydrate consumption in the CON group, while the lipid and protein consumption was lower than that in the CON and NCS groups. However, the intake of non-caloric soda did not significantly alter the total solid foods and energy consumption, body weight gain, and liposomal index when compared to the CON group. Owing to the greater consumption of soft drinks, the animals in the CS and NCS groups, which received only standard feed as solid food, consumed less water than CON. Water was replaced by caloric soda as it has a high content of sucrose (a simple carbohydrate) and is highly palatable. This is considered one of the main contributors to the increase in the number of overweight and obese people $[3,29,30]$ and abdominal adiposity [31]. Similar results were found in another study by our group, which analyzed the effects of caloric and non-caloric soft drink consumption during 17 weeks of treatment in rats [21]. A study on the food consumption in the Brazilian population, through a telephone survey, identified an increase in caloric soft drink consumption from $60 \%$ in 2007 to $67 \%$ in 2009 [32].

The dopaminergic system (reward system) may be involved in the increase in soda consumption, which in turn induces gastric distension and decreases the standard feed intake. The reward system is complex and comprises several phases. In the anticipatory phase, expectations are created regarding food/sucrose, followed by the acquisition phase with decision-making assessing the benefit-risk, followed by consumption. In this phase, positive feedback is generated through sensory analysis in the first contact with food, thus increasing motivation and appetite. Finally, the post-consumption phase runs until the beginning of the next cycle [10]. When palatable foods such as those rich in sucrose are consumed, there is an increase in dopamine release in the nucleus accumbens, which stimulates food preference and increases sucrose intake, playing these roles in the preparatory and food consumption phases [33]. It is important to note that the reward mechanism involved in the intake of palatable food (such as sucrose) is not only related to the nucleus accumbens, but other structures such as the dorsal striatum and the orbitofrontal cortex are also strongly involved [34]. Taste receptors found in the oral cavity can also be expressed in epithelial cells of the intestine and hypothalamus. The feeling of satisfaction when eating palatable food, instead of generating acute pleasure, lasts for some time, which most likely contributes to the desire to eat again [35]. Another factor that seems to contribute to reward generation during and after a meal is the action of nutrient sensors in the gastrointestinal tract $[9,35]$.

A previous clinical study showed that the consumption of ultra-processed foods led to an increase in carbohydrate and fat intake and a reduction in protein consumption, resulting in an increase in the weight of the participants [36]. A Brazilian study identified that the prevalence of obesity in 2019 exceeded twice the values registered in 20022003, among both men (from $9.6 \%$ to $22.8 \%$ ) and women (from $14.5 \%$ to $30.2 \%$ ). Obese people represent more than a third of the total overweight men and almost half of the overweight women [37].

The caloric soda intake and the consequent decrease in solid food consumption can be explained by the high palatability and satiety provided by caloric soda. Postprandial hyperglycemia activates satiety nuclei in the ventromedial hypothalamus, which inhibits the nucleus related to the feeding of the lateral hypothalamus and induces food intake suppression, which is known as the hunger glycostatic theory [38]. The caloric soda consumption amount in the CS group was higher than that in CD + CS group because the latter, in addition to receiving caloric soda, received solid palatable food in the cafeteria diet. 
The total solid food intake was similar for the groups that received the cafeteria diet, but higher than the CON, CS, and NCS groups in detriment of the standard feed consumption, demonstrating the high intake of the cafeteria diet. This resulted in high lipid and low protein consumption, leading to a $450 \%$ increase in the lipid consumption and a $50 \%$ reduction in the protein intake. The high palatability of the cafeteria diet contributes to increased energy consumption, triggering an increase in body fat, and consequent obesity in animal models [19, 27, 39-41] and in humans [42]. Our study showed a significant increase in the weight of animals receiving a cafeteria diet. These animals showed a $60 \%$ increase in body weight compared to animals in the control group, increased body fat, triglyceride, and leptin levels. Likewise, it was observed by another study carried out with Wistar rats fed a high-fat diet [43]. Thus, this diet increased the metabolic risk, as was observed, demonstrating HOMA changes. It should be noted that soft drink consumption can decrease adherence to healthy diets by decreasing the intake of nutrients such as fibers and micronutrients (e.g., folic acid and calcium) among children and young people $[26,44,45]$.

The carbohydrate and nitrogen balance is facilitated by the body's ability to adjust the glucose and amino acid oxidation rates, respectively, in relation to food consumption. In the case of fats, however, the increase in consumption is not oxidized to the same extent. Approximately $96 \%$ of the lipids ingested in the diet induce a positive lipid balance and are stored as body fat $[46,47]$. Another important result of our study is related to the increase in sodium levels among animals consuming the cafeteria diet. This result was expected because processed foods are rich in sodium content.

The use of drinks sweetened with ingredients that do not provide calories is controversial according to some authors. This study found that despite having solid food consumption and total energy like those in the CD and CD + CS groups, the CD + NCS group had a significantly lower LI, demonstrating less visceral fat deposition. The results of this study were different from those obtained by some other studies which identified that artificial sweeteners caused an increase in body weight in the group that received sucrose, but the total energy consumption was not significantly different $[48,49]$. However, a study carried out in Denmark observed an increase in weight and body fat in individuals who received drinks and foods sweetened with sucrose, and there was a reduction in body weight and body fat in individuals who received drinks and foods sweetened with artificial sweeteners [50]. Similarly, another research found less weight gain in rats that received cola drinks and a high-fat diet as compared to controls who received the same diet but drank water for 28 weeks. The lower weight gain was attributed to the possible increase in muscle thermogenesis induced by caffeine in cola soft drinks [51]. Other studies have also shown beneficial effects of caffeine on the adiposity of animals fed high-fat diets, demonstrating a reduction in body fat mass and percentage of body fat, possibly due to increased lipolysis via catecholamines [52,53]. The lower LI in the CD + NCS group may be related to the lower insulinogenic effect of the non-caloric soda due to the greater presence of caffeine in the drink and the $17 \%$ reduction in carbohydrates compared to the CD + CS group. Caffeine generates a lipolytic effect by stimulating the release of adrenaline by the adrenal glands, thereby reducing lipogenesis [54, 55]. Another study demonstrated beneficial effects of caffeine consumption on health and a negative association with the incidence of DM2, as well as in helping control body weight [56].

This result suggests that the consumption of caffeine present in non-caloric cola-type soda may help prevent obesity, which is related to the absence of sucrose and caffeine content. However, further studies are needed on the effects of consuming caloric and non-caloric soda with a cafeteria diet on metabolism. It is also necessary to compare the effect of sugary drink intake with that of artificially sweetened, caffeine-free drinks associated with a cafeteria diet.

\section{Strength and Limits}


The strengths of this study are the significant changes in normal feeding patterns due to the consumption of caloric soft drink and ultra-processed foods (cafeteria diet). Due to its high palatability, the cafeteria diet caused hyperphagia, increased lipid consumption (450\%), decreased protein intake (50\%), resulting in a $60 \%$ increase in body weight. On the other hand, the non-caloric soft drink reduced the visceral fat, suggesting its use in obesity prevention. As a limitation of the study, we cannot affirm for sure that the non-caloric soda caffeine was responsible for the visceral fat reduction in animals. Therefore, specific studies are necessary to compare the sugary caffeinefree soft drink intake effect with that artificially sweetened caffeine-free soda, associated with a cafeteria diet.

\section{What is already known on this subject?}

Previous clinical and animal studies showed that ultra-processed food consumption led to an increase in carbohydrate and fat intake and a reduction in protein consumption, increasing the bodyweight of the individuals. But the effect of the association of caloric and non-caloric soft drink intake with ultra-processed and highly palatable food on the eating behavior and metabolic parameters was still to be assessed.

\section{What your study adds?}

The study demonstrated a great increase in caloric soft drink consumption concerning the non-caloric soft drink, showed that the caloric soda intake had a negative influence on the standard food (healthy food) consumption, while the non-caloric soda intake did not interfere. It was not yet known that the non-caloric soft drink intake doesn't have the same effect on visceral fat deposition compared to the caloric soft drink consumption in rats fed a cafeteria diet.

\section{Conclusion}

During the study period, the supply of balanced food along with caloric soda intake reduced solid food and water consumption and increased energy consumption and total liquid intake. Thus, caloric soda intake had a negative influence on the quantity and quality of consumed solid foods, causing a nutritional imbalance. Non-caloric soda intake did not alter food intake or energy consumption, but it did lead to higher liquid consumption and lesser water consumption. The animals that received a cafeteria diet consumed more processed foods offered and did not ingest much standard feed, making their food intake low in nutritional value and causing an increase in the consumption of energy from sugars and lipids, greater weight gain, and visceral fat. On the other hand, animals that received the cafeteria diet and non-caloric sodas showed a reduction in visceral fat quantity compared to the animals from the other two groups that received the cafeteria diet. It has not yet been possible to identify a specific food or ingredient that is capable of triggering addictive behavior in humans, but palatable foods are the likely candidates. Studies with validated instruments are necessary to analyze food consumption to aid the development of strategies for treating inappropriate eating behaviors.

\section{Declarations}

\section{Author Contributions:}

MEKH coordinated the study design, was responsible for the experiment execution, analysis, interpretation of data, literature review, and drafted the manuscript.

ICM - contributed to the experiment execution, analysis, interpretation of data, literature review, and drafted the manuscript. 
RUT - contributed to the experiment execution, literature review, analysis, interpretation of data, and drafted the manuscript.

ROF - contributed to the experiment execution, statistical analysis, data analysis, and revised the manuscript critically for important intellectual content.

JFG - contributed to the experiment execution, statistical analysis, data analysis, and revised the manuscript critically for important intellectual content.

GLS - contributed to the study design, data analysis, and revised the manuscript critically for important intellectual content.

ILT - contributed to the data analysis and revised the manuscript critically for important intellectual content.

All the authors read, commented on, and approved the final manuscript.

\section{Acknowledgments}

The authors would like to thank Vanessa Giacomeli, Thais Thompsen Silveira, Sabrina Fernandes, and Daniele Harter for helping with the animals' treatment and data acquisition.

\section{Compliance with ethical standards}

Ethical approval: The experiments and procedures were approved by the Institutional Animal Care and Use Committee (protocol No 13,0136), were compliant with Brazilian guidelines involving the use of animals in research (Federal Law 11,794/2008), and were performed in accordance with the International Guidelines for Animal Welfare.

Funding/Support: The funding for this project was provided by the Conselho Nacional de Desenvolvimento Científico e Tecnológico - CNPq-BR (Dr. Hagen Grant - 482296/2013-5, Dr. Torres Grant - 305395/2018-1) and FIPE/HCPA (Dr. Hagen Grant no. 13-0136). The authors thank the CNPq and FIPE/HCPA for the financial support.

\section{Conflict of interest}

The authors declare that they have no conflicts of interest. The authors alone are responsible for the content and preparation of this paper.

\section{References}

1. Harbury CM, Verbruggen EE, Callister R, Collins CE (2016) What do individuals with morbid obesity report as a usual dietary intake? A narrative review of available evidence. Clin Nutr ESPEN 13:e15-e22. https://doi.org/10.1016/j.clnesp.2016.02.001

2. Huang C, Huang J, Tian Y, et al (2014) Sugar sweetened beverages consumption and risk of coronary heart disease: A meta-analysis of prospective studies. Atherosclerosis 234:11-16.

https://doi.org/10.1016/j.atherosclerosis.2014.01.037

3. Malik VS, Schulze MB, Hu FB (2006) Intake of sugar-sweetened beverages and weight gain: a systematic review. Am J Clin Nutr 84:274-88

4. Malik VS, Popkin BM, Bray GA, et al (2010) Sugar-sweetened beverages and risk of metabolic syndrome and type 2 diabetes: a meta-analysis. Diabetes Care 33:2477-81. https://doi.org/10.2337/dc10-1079. 
5. Milei J, Otero Losada M, Gómez Llambí H, et al (2011) Chronic cola drinking induces metabolic and cardiac alterations in rats. World J Cardiol 3:111-6. https://doi.org/10.4330/wjc.v3.i4.111

6. Monteiro CA (2009) Nutrition and health. The issue is not food, nor nutrients, so much as processing. Public Health Nutr 12:729-731. https://doi.org/10.1017/S1368980009005291

7. Monteiro CA, Moubarac JC, Levy RB, et al (2018) Household availability of ultra-processed foods and obesity in nineteen European countries. Public Health Nutr 21:18-26. https://doi.org/10.1017/S1368980017001379

8. Schmidt MI, Duncan BB, E Silva GA, et al (2011) Chronic non-communicable diseases in Brazil: Burden and current challenges. Lancet 377:1949-1961. https://doi.org/10.1016/S0140-6736(11)60135-9

9. Berthoud H, Lenard NR, Shin AC (2011) Food reward, hyperphagia, and obesity. Am J Physiol Regul Integr Comp Physiol 300:1266-1277. https://doi.org/10.1152/ajpregu.00028.2011.

10. Hajnal A, Smith GP, Norgren R (2004) Oral sucrose stimulation increases accumbens dopamine in the rat. Am J Physiol - Regul Integr Comp Physiol 286:31-37. https://doi.org/10.1152/ajpregu.00282.2003

11. Norgren R, Hajnal A, Mungarndee SS (2006) Gustatory reward and the nucleus accumbens. Physiol Behav 89:531-535. https://doi.org/10.1016/j.physbeh.2006.05.024

12. Wiss DA, Brewerton TD (2017) Incorporating food addiction into disordered eating: the disordered eating food addiction nutrition guide (DEFANG). Eat Weight Disord 22:49-59. https://doi.org/10.1007/s40519-016-0344-y

13. Schulte EM, Avena NM, Gearhardt AN (2015) Which foods may be addictive? The roles of processing, fat content, and glycemic load. PLoS One 10:1-18. https://doi.org/10.1371/journal.pone.0117959

14. Rogers, Peter J. \& Brunstrom JM (2016) Appetite and energy balancing. Physiol Behav 164:465-471. https://doi.org/10.1016/j.physbeh.2016.03.038

15. Monteiro CA, Levy RB, Claro RM, et al (2010) A new classification of foods based on the extent and purpose of their processing. Cad Saude Publica 26:2039-2049. https://doi.org/10.1590/S0102-311X2010001100005

16. Berner LA, Avena NM, Hoebel BG (2008) Bingeing, self-restriction, and increased body weight in rats with limited access to a sweet-fat diet. Obesity 16:1998-2002. https://doi.org/10.1038/oby.2008.328

17. Avena NM, Rada P, Hoebel BG (2009) Sugar and Fat Bingeing Have Notable Differences in Addictive-like Behavior. J Nutr 139:623-628. https://doi.org/10.3945/jn.108.097584

18. Goularte JF, Ferreira MBC, Sanvitto GL (2012) Effects of food pattern change and physical exercise on cafeteria diet-induced obesity in female rats. Br J Nutr 108:1511-1518. https://doi.org/10.1017/S0007114511006933

19. Macedo IC, Medeiros LF, Oliveira C, et al (2012) Cafeteria diet-induced obesity plus chronic stress alter serum leptin levels. Peptides 38:189-196. https://doi.org/10.1016/j.peptides.2012.08.007

20. Sampey BP, Vanhoose AM, Winfield HM, et al (2011) Cafeteria diet is a robust model of human metabolic syndrome with liver and adipose inflammation: Comparison to high-fat diet. Obesity 19:1109-1117.

https://doi.org/10.1038/oby.2011.18

21. Cony, K.V., Goularte, J.F., Souza, C.G., Sanvitto. G.S., Hagen MEK (2016) Scientia Medica. Sci Me 26:1-8. https://doi.org/10.15448/1980-6108.2016.2.21828

22. Milagro Fl, Campión J, Martíez JA (2006) Weight gain induced by high-fat feeding involves increased liver oxidative stress. Obesity 14:1118-1123. https://doi.org/10.1038/oby.2006.128

23. Macedo IC, Rozisky JR, Oliveira C, et al (2015) Chronic stress associated with hypercaloric diet changes the hippocampal BDNF levels in male Wistar rats. Neuropeptides 51:75-81.

https://doi.org/10.1016/j.npep.2015.01.002

Page $11 / 17$ 
24. Hall CB, Lukaski HC, Marchello MJ (1989) Estimation of rat body composition using tetrapolar bioelectrical impedance analysis. Nutr Rep Int 39:627-633

25. Cacho J, Sevillano J, De Castro J, et al (2008) Validation of simple indexes to assess insulin sensitivity during pregnancy in Wistar and Sprague-Dawley rats. Am J Physiol - Endocrinol Metab 295:1269-1276. https://doi.org/10.1152/ajpendo.90207.2008

26. Ballew C, Kuester S, Gillespie C (2000) Beverage choices affect adequacy of children's nutrient intakes. Arch Pediatr Adolesc Med 154:1148-1152. https://doi.org/10.1001/archpedi.154.11.1148

27. Carvalho MHC de, Colaço AL, Fortes ZB (2006) Citocinas, disfunção endotelial e resistência à insulina. Arq Bras Endocrinol Metabol 50:304-312. https://doi.org/10.1590/S0004-27302006000200016

28. Kim SY, Sim S, Park B, et al (2016) Dietary habits are associated with school performance in adolescents. Med (United States) 95:1-10. https://doi.org/10.1097/MD.0000000000003096

29. Miller C, Ettridge K, Wakefield M, et al (2020) An Australian Population Study. Nutrients 12:

30. Pan A, Hu FB (2011) Effects of carbohydrates on satiety: differences between liquid and solid food. Curr Opin Clin Nutr Metab Care 14:385-390. https://doi.org/10.1097/MC0.0b013e328346df36

31. Funtikova AN, Subirana I, Gomez SF, et al (2015) Soft Drink Consumption Is Positively Associated with Increased Waist Circumference and 10-Year Incidence of Abdominal Obesity in Spanish Adults. J Nutr 145:328-34. https://doi.org/10.3945/jn.114.205229.TABLE

32. Souza ADM, Bezerra IN, Cunha DB, Sichieri R (2011) Avaliação dos marcadores de consumo alimentar do VIGITEL (2007-2009). Rev Bras Epidemiol 14:44-52. https://doi.org/10.1590/S1415-790X2011000500005

33. Smith GP (2004) Accumbens dopamine mediates the rewarding effect of orosensory stimulation by sucrose. Appetite 43:11-13. https://doi.org/10.1016/j.appet.2004.02.006

34. Murray S, Tulloch A, Gold MS, Avena NM (2014) Hormonal and neural mechanisms of food reward, eating behaviour and obesity. Nat Rev Endocrinol 10:540-552. https://doi.org/10.1038/nrendo.2014.91

35. Sclafani A, Ackroff K (2004) The relationship between food reward and satiation revisited. Physiol Behav 82:89-95. https://doi.org/10.1016/j.physbeh.2004.04.045

36. Hall KD, Ayuketah A, Brychta R, et al (2019) Ultra-Processed Diets Cause Excess Calorie Intake and Weight Gain: An Inpatient Randomized Controlled Trial of Ad Libitum Food Intake. Cell Metab 30:67-77.e3. https://doi.org/10.1016/j.cmet.2019.05.008

37. Brasil (2020) Pesquisa nacional de saúde: 2019: atenção primária à saúde e informações antropométricas: Brasil / IBGE, Coordenação de Trabalho e Rendimento. -, IBGE. Rio de Janeiro

38. Mayer J, Thomas DW (1967) Regulation of Food Intake and Obesity. Science (80- ) 156:328-337. https://doi.org/10.1126/science.156.3773.328

39. Akyol A, McMullen S, Langley-Evans SC (2012) Glucose intolerance associated with early-life exposure to maternal cafeteria feeding is dependent upon post-weaning diet. Br J Nutr 107:964-978. https://doi.org/10.1017/S0007114511003916

40. Júnior DACP, Seraphim PM (2012) Cafeteria diet intake for fourteen weeks can cause obesity and insulin resistance in Wistar rats Dieta de cafeteria por quatorze semanas pode causar obesidade e resistência insulínica em ratos Wistar. Rev Nutr 25:313-319. https://doi.org/10.1590/S1415-52732012000300001

41. Castro H, Pomar CA, Picó C, et al (2015) Cafeteria diet overfeeding in young male rats impairs the adaptive response to fed/fasted conditions and increases adiposity independent of body weight. Int J Obes 39:430-437. https://doi.org/10.1038/ijo.2014.125

Page $12 / 17$ 
42. Schröder H, Mendez MA, Ribas L, et al (2014) Caloric beverage drinking patterns are differentially associated with diet quality and adiposity among Spanish girls and boys. Eur J Pediatr 173:1169-1177. https://doi.org/10.1007/s00431-014-2302-x

43. Bahceci M, Tuzcu A, Akkus M, et al (1999) The effect of high-fat diet on the development of obesity and serum leptin level in rats. Eat Weight Disord 4:128-132. https://doi.org/10.1007/BF03339728

44. Yamada M, Murakami K, Sasaki S, et al (2008) Soft Drink Intake Is Associated with Diet Quality Even among Young Japanese Women with Low Soft Drink Intake. J Am Diet Assoc 108:1997-2004. https://doi.org/10.1016/j.jada.2008.09.033

45. Libuda L, Alexy U, Buyken AE, et al (2009) Consumption of sugar-sweetened beverages and its association with nutrient intakes and diet quality in German children and adolescents. Br J Nutr 101:1549-1557. https://doi.org/10.1017/S0007114508094671

46. Flatt JP (1987) Dietary fat, carbohydrate balance, and weight maintenance: effects of exercise. Am Soc Clin Nutr 45:296-306. https://doi.org/https://doi.org/10.1093/ajcn/45.1.296

47. Flatt JP (1995) Use and storage of Carbohydrate and Fat. Am J Clin Ntur 61:952S-9S. https://doi.org/https://doi.org/10.1093/ajcn/61.4.952s

48. Swithers SE, Davidson TL (2008) A Role for Sweet Taste: Calorie Predictive Relations in Energy Regulation by Rats. Behav Neurosci 122:161-173. https://doi.org/10.1037/0735-7044.122.1.161

49. Feijó F de M, Ballard CR, Foletto KC, et al (2013) Saccharin and aspartame, compared with sucrose, induce greater weight gain in adult Wistar rats, at similar total caloric intake levels. Appetite 60:203-207. https://doi.org/10.1016/j.appet.2012.10.009

50. Raben A, Vasilaras TH, Møller AC, Astrup A (2002) Sucrose compared with artificial sweeteners: Different effects on ad libitum food intake and body weight after $10 \mathrm{wk}$ of supplementation in overweight subjects. Am $\mathrm{J}$ Clin Nutr 76:721-729. https://doi.org/10.1093/ajcn/76.4.721

51. Choi SB, Park CH, Park S (2002) Effect of cola intake on insulin resistance in moderate fat-fed weaning male rats. J Nutr Biochem 13:727-733. https://doi.org/10.1016/S0955-2863(02)00216-4

52. Kobayashi-Hattori K, Mogi A, Matsumoto Y, Takita T (2005) Effect of caffeine on the body fat and lipid metabolism of rats fed on a high-fat diet. Biosci Biotechnol Biochem 69:2219-2223.

https://doi.org/10.1271/bbb.69.2219

53. Inoue H, Kobayashi-Hattori K, Horiuchi Y, et al (2006) Regulation of the body fat percentage in developmentalstage rats by methylxanthine derivatives in a high-fat diet. Biosci Biotechnol Biochem 70:1134-1139. https://doi.org/10.1271/bbb.70.1134

54. Smits P, Pieters G, Thien T (1986) The role of epinephrine in the circulatory effects of coffee. Clin Pharmacol Ther 40:431-437. https://doi.org/10.1038/clpt.1986.203

55. Hulston CJ, Jeukendrup AE (2008) Substrate metabolism and exercise performance with caffeine and carbohydrate intake. Med Sci Sports Exerc 40:2096-2104. https://doi.org/10.1249/MSS.0b013e318182a9c7

56. Heckman MA, Weil J, de Mejia EG (2010) Caffeine (1, 3, 7-trimethylxanthine) in foods: A comprehensive review on consumption, functionality, safety, and regulatory matters. J Food Sci 75:77-87.

https://doi.org/10.1111/j.1750-3841.2010.01561.x

\section{Tables}

Table 1. Nutrients daily average consumption during 12 weeks treatment 


\begin{tabular}{|c|c|c|c|c|c|c|c|c|}
\hline & \multirow{2}{*}{$\begin{array}{l}\text { Energy } \\
\mathrm{kJ} / 100 \mathrm{~g}\end{array}$} & \multicolumn{2}{|c|}{ Carbohydrate } & \multicolumn{2}{|l|}{ Protein } & \multicolumn{2}{|l|}{ Lipids } & \multirow{2}{*}{$\begin{array}{l}\text { Sodium } \\
\mathrm{mg} / 100 \mathrm{~g}\end{array}$} \\
\hline & & $\mathrm{g} / 100 \mathrm{~g}$ & $\begin{array}{l}\text { Percentage } \\
\text { of energy }\end{array}$ & $\mathrm{g} / 100 \mathrm{~g}$ & $\begin{array}{l}\text { Percentage } \\
\text { of energy }\end{array}$ & $\mathrm{g} / 100 \mathrm{~g}$ & $\begin{array}{l}\text { Percentage } \\
\text { of energy }\end{array}$ & \\
\hline $\begin{array}{l}\text { Standard } \\
\text { chow }^{\text {a }}\end{array}$ & $1,234.0$ & 40.5 & 55.0 & 16.2 & 22.0 & 1.5 & 4.5 & 0.27 \\
\hline $\begin{array}{l}\text { Snack } \\
\text { Yokitos }{ }^{b}\end{array}$ & $1,916.0$ & 64.0 & 48.4 & 6.8 & 4.2 & 19.2 & 47.1 & 640.0 \\
\hline $\begin{array}{l}\text { Sandwich } \\
\text { cookies } \\
\text { strawberry } \\
\text { c }\end{array}$ & $2,016.0$ & 70.0 & 54.4 & 5.0 & 4.4 & 20.0 & 38.6 & 223.3 \\
\hline $\begin{array}{l}\text { Wafer } \\
\text { chocolate } \\
\text { d }\end{array}$ & $1,920.0$ & 53.3 & 48.4 & 4.7 & 3.6 & 25.0 & 48.1 & 163.3 \\
\hline $\begin{array}{l}\text { Condensed } \\
\text { milk }^{\mathrm{e}}\end{array}$ & $1,345.0$ & 55.0 & 68.7 & 7.5 & 9.4 & 8.0 & 22.5 & 90.0 \\
\hline $\begin{array}{l}\text { Frankfurter } \\
f\end{array}$ & 820.0 & 4.8 & 8.7 & 14.0 & 24.9 & 13.6 & 66.3 & $1,082.0$ \\
\hline $\begin{array}{l}\text { Soft drink } \\
\text { Cola } \\
\text { traditional } \\
\mathrm{g}\end{array}$ & 178.0 & 11.0 & 98.8 & 0.0 & 0.0 & 0.0 & 0.0 & 5.0 \\
\hline $\begin{array}{l}\text { Soft drink } \\
\text { Cola Zero }{ }^{g}\end{array}$ & 0.0 & 0.0 & 0.0 & 0.0 & 0.0 & 0.0 & 0.0 & 28.0 \\
\hline
\end{tabular}

Data obtained from the manufacturer's website

${ }^{a}$ Nuvilab CR-1, Brazil; ${ }^{b}$ Yoki, Brazil; ${ }^{c}$ Kraft Foods Brasil; ${ }^{\mathrm{d}}$ Bauducco, Brazil; ${ }^{\mathrm{e}}$ Elegê, Brazil; ${ }^{\mathrm{f}}$ Excelsior, Brazil; ${ }^{\mathrm{g}}$ (CocaCola, Brazil).

Table 2. Nutrients daily average consumption during 12 weeks treatment 


\begin{tabular}{|lllllll|}
\hline & $\begin{array}{l}\mathrm{CON} \\
(\mathrm{n}=10)\end{array}$ & $\begin{array}{l}\mathrm{CS} \\
(\mathrm{n}=10)\end{array}$ & $\begin{array}{l}\mathrm{NCS} \\
(\mathrm{n}=10)\end{array}$ & $\mathrm{CD}(\mathrm{n}=10)$ & $\begin{array}{l}\mathrm{CD}+\mathrm{CS} \\
(\mathrm{n}=10)\end{array}$ & $\begin{array}{l}\mathrm{CD}+\mathrm{NCS} \\
(\mathrm{n}=10)\end{array}$ \\
\hline Solid carbohydrate $(\mathrm{g})$ & $14.6 \pm 0.3^{\mathrm{a}}$ & $10.2 \pm 0.4^{\mathrm{b}}$ & $14.5 \pm 0.4^{\mathrm{a}}$ & $12.5 \pm 0.5^{\mathrm{c}}$ & $10.6 \pm 0.4^{\mathrm{b}}$ & $13.3 \pm 0.9^{\mathrm{a}, \mathrm{c}}$ \\
\hline $\begin{array}{l}\text { Soft drink } \\
\text { carbohydrate(g) }\end{array}$ & - & $9.3 \pm 0.7^{\mathrm{a}}$ & - & - & $5.5 \pm 0.3^{\mathrm{b}}$ & - \\
\hline Total carbohydrate (g) & $14.6 \pm 0.3^{\mathrm{a}, \mathrm{c}}$ & $19.5 \pm 0.5^{\mathrm{b}}$ & $14.5 \pm 0.4^{\mathrm{a}, \mathrm{c}}$ & $12.5 \pm 0.5^{\mathrm{a}}$ & $16.1 \pm 0.6^{\mathrm{c}}$ & $13.3 \pm 0.9^{\mathrm{a}}$ \\
\hline Protein (g) & $5.8 \pm 0.12^{\mathrm{a}}$ & $4.1 \pm 0.15^{\mathrm{b}}$ & $5.8 \pm 0.17^{\mathrm{a}}$ & $2.9 \pm 0.16^{\mathrm{c}}$ & $2.7 \pm 0.19^{\mathrm{c}}$ & $2.9 \pm 0.1^{\mathrm{c}}$ \\
\hline Lipid (g) & $1.06 \pm 0.02^{\mathrm{a}}$ & $0.7 \pm 0.02^{\mathrm{a}}$ & $1.1 \pm 0.03^{\mathrm{a}}$ & $4.8 \pm 0.2^{\mathrm{b}}$ & $4.4 \pm 0.12^{\mathrm{b}}$ & $4.5 \pm 0.2^{\mathrm{b}}$ \\
\hline Solids Sodium (mg) & $71.6 \pm 1.5^{\mathrm{a}}$ & $49.9 \pm 1.8^{\mathrm{a}}$ & $71.4 \pm 2.1^{\mathrm{a}}$ & $180.7 \pm 10.9^{\mathrm{b}}$ & $189.6 \pm 13.7^{\mathrm{c}}$ & $161.0 \pm 8.7^{\mathrm{b}}$ \\
\hline Liquids Sodium (mg) & - & $4.3 \pm 0.3^{\mathrm{a}}$ & $3.8 \pm 0.3^{\mathrm{a}}$ & - & $2.8 \pm 0.3^{\mathrm{b}}$ & $4.5 \pm 0.3^{\mathrm{a}}$ \\
\hline & & & & & & \\
\hline Total Sodium (mg) & $71.6 \pm 1.5^{\mathrm{a}}$ & $54.3 \pm 1.6^{\mathrm{a}}$ & $75.2 \pm 2.3^{\mathrm{a}}$ & $180.7 \pm 10.9^{\mathrm{b}}$ & $192.0 \pm 13.7^{\mathrm{b}}$ & $165.6 \pm 8.9^{\mathrm{b}}$ \\
\hline Caffeine $(\mathrm{mg})$ & - & $8.54 \pm 0.9^{\mathrm{a}}$ & $2.7 \pm 0.6^{\mathrm{b}}$ & - & $5.2 \pm 0.8^{\mathrm{c}}$ & $3.24 \pm 1.5^{\mathrm{b}, \mathrm{c}}$ \\
\hline
\end{tabular}

Data expressed as mean \pm SE of ten animals/group. CON (control); CS (caloric soft drink); NCS (non-caloric soft drink); $C D$ (cafeteria diet); $C D+C S$ (CD+caloric soft drink); $C D+N C S$ (CD+non-caloric soft drink). ${ }^{\text {a, } b, c}$ Different letters represent a significant difference $(P<0.05$; one way ANOVA with Tukey post hoc test. Student's $t$ test was used for carbohydrate analysis in soft drinks).

Table 3. Serum biochemical levels at the end of the experiment (12th week)

\begin{tabular}{|c|c|c|c|c|c|c|}
\hline & $\begin{array}{l}\text { CON } \\
(n=10)\end{array}$ & $\begin{array}{l}\text { CS } \\
(n=10)\end{array}$ & $\begin{array}{l}\text { NCS } \\
(n=10)\end{array}$ & $\begin{array}{l}C D \\
(n=10)\end{array}$ & $\begin{array}{l}C D+C S \\
(n=10)\end{array}$ & $\begin{array}{l}\text { CD+NCS } \\
(n 10)\end{array}$ \\
\hline $\begin{array}{l}\text { Glucose } \\
\text { (mg/dL) }\end{array}$ & $105.9 \pm 2.15^{\mathrm{a}}$ & $105.6 \pm 2.15^{\mathrm{a}}$ & $104.0 \pm 2.10^{\mathrm{a}}$ & $111.1 \pm 2.15^{\mathrm{a}}$ & $111.8 \pm 2.3^{\mathrm{a}}$ & $105.4 \pm 2.1^{\mathrm{a}}$ \\
\hline HOMA-IR & $0.059 \pm 0.01^{\mathrm{a}}$ & $0.046 \pm 0.01^{\mathrm{a}}$ & $0.053 \pm 0.01^{\mathrm{a}}$ & $0.123 \pm 0.0^{\mathrm{b}}$ & $0.136 \pm 0.01^{\mathrm{b}}$ & $0.090 \pm 0.01^{\mathrm{a}, \mathrm{b}}$ \\
\hline $\begin{array}{l}\text { Total } \\
\text { Cholesterol } \\
\text { (mg/dL) }\end{array}$ & $69.8 \pm 1.3^{\mathrm{a}}$ & $70.8 \pm 1.3^{a}$ & $72.0 \pm 1.3^{a}$ & $68.9 \pm 1.3^{a}$ & $73.2 \pm 1.4^{a}$ & $72.3 \pm 1.3^{\mathrm{a}}$ \\
\hline HDL-c (mg/dL) & $21.6 \pm 1.0^{\mathrm{a}}$ & $21.6 \pm 0.9^{a}$ & $20.5 \pm 0.9^{a}$ & $20.7 \pm 1.0^{\mathrm{a}}$ & $20.7 \pm 1.0^{\mathrm{a}}$ & $20.1 \pm 0.9^{a}$ \\
\hline $\begin{array}{l}\text { Non HDL-c } \\
(\mathrm{mg} / \mathrm{dL})\end{array}$ & $48.2 \pm 1.5^{a}$ & $49.2 \pm 1.4^{\mathrm{a}}$ & $51.5 \pm 1.5^{a}$ & $48.3 \pm 2.0^{a}$ & $52.5 \pm 1.9^{a}$ & $52.2 \pm 1.2^{a}$ \\
\hline $\begin{array}{l}\text { Triglycerides } \\
(\mathrm{mg} / \mathrm{dL})\end{array}$ & $65.7 \pm 9.9^{a}$ & $67.5 \pm 9.9^{a}$ & $69.7 \pm 9.9^{a}$ & $127.9 \pm 10.0^{\mathrm{b}}$ & $118.3 \pm 10.5^{b}$ & $89.9 \pm 9.9^{a, b}$ \\
\hline Insulin (ng/mL) & $1.30 \pm 0.2^{\mathrm{a}}$ & $1.10 \pm 0.2^{\mathrm{a}}$ & $1.20 \pm 0.3^{\mathrm{a}}$ & $2.60 \pm 0.5^{b}$ & $3.00 \pm 0.5^{b}$ & $1.90 \pm 0.4^{a, b}$ \\
\hline Leptin (ng/mL) & $2.92 \pm 1.8^{\mathrm{a}}$ & $2.31 \pm 1.8^{a}$ & $3.22 \pm 1.8^{\mathrm{a}}$ & $13.33 \pm 1.9^{b}$ & $14.64 \pm 1.9^{b}$ & $8.49 \pm 1.7^{a, b}$ \\
\hline
\end{tabular}


Data expressed as mean \pm SE of ten animals/group. CON (control); CS (caloric soft drink); NCS (non-caloric soft drink); $C D$ (cafeteria diet); $C D+C S$ (CD+caloric soft drink); $C D+N C S$ (CD+non-caloric soft drink). ${ }^{a}, b, c$ Different letters represent a significant difference ( $P<0.05$; one way ANOVA with Tukey post hoc test). HOMA-IR (homeostasis model assessment of insulin resistance); HDL-c (high-density lipoprotein); Non HDL-c (Non high-density lipoprotein).

\section{Figures}
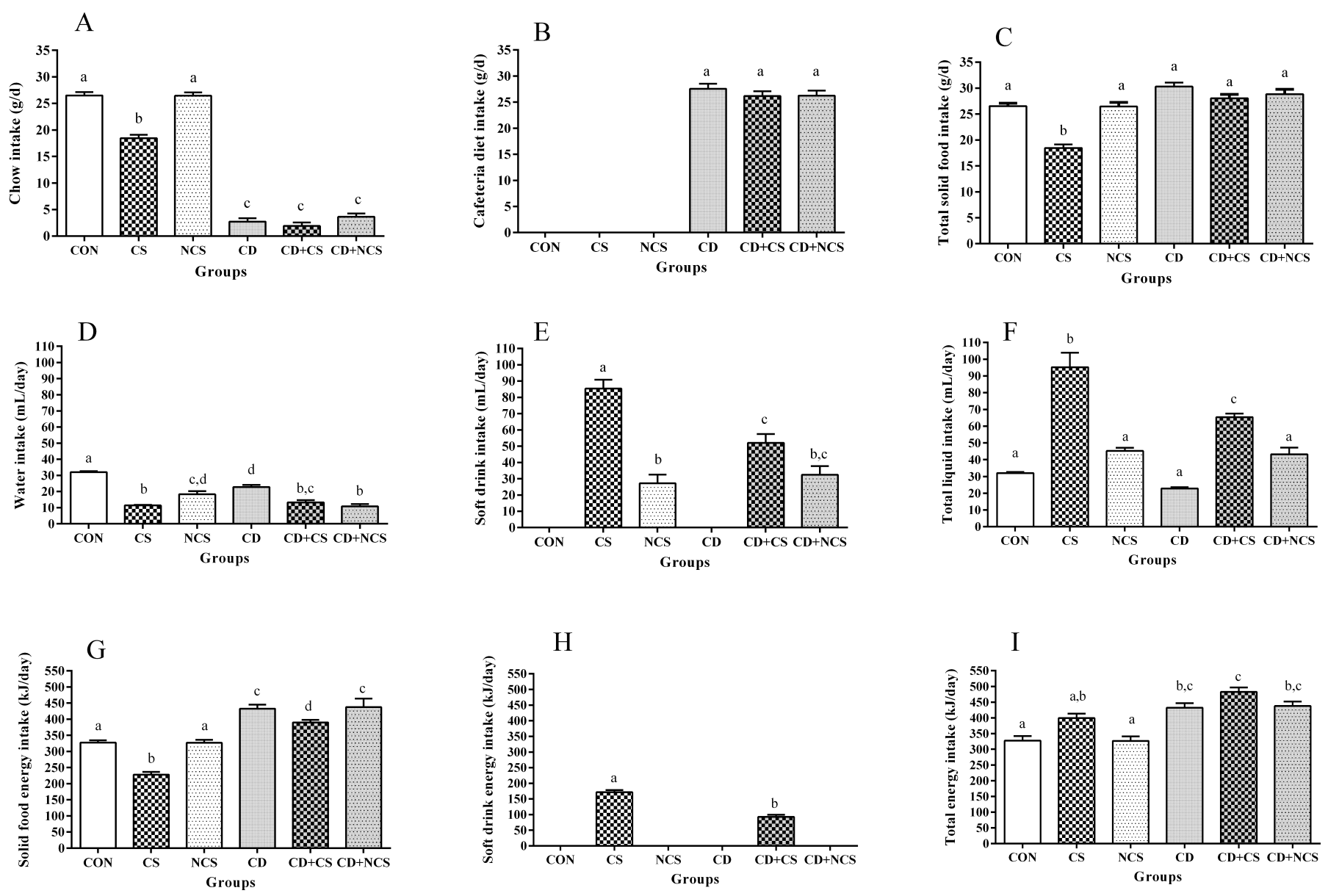

\section{Figure 1}

Average daily intake of: (A) standard chow (g/d), (B) Cafeteria diet (g/d), (C) Total solid food (g/d), (D) water ( $\mathrm{mL} /$ day), (E) Soft drink (mL/day), (F) Total liquid (mL/day), (G) Solid food energy (kJ/day), (H) Soft drink energy ( $\mathrm{kJ} /$ day), and (I) Total energy (kJ/day) during 12 weeks treatment. Data expressed as mean $\pm \mathrm{SE}$ of ten animals/group. CON (control); CS (caloric soft drink); NCS (non-caloric soft drink); CD (cafeteria diet); CD+CS (CD + caloric soft drink); NCS+CD (CD + non-caloric soft drink). a, b, c Different letters represent a significant difference $(p<0.05$; one way ANOVA with Tukey post hoc test) 

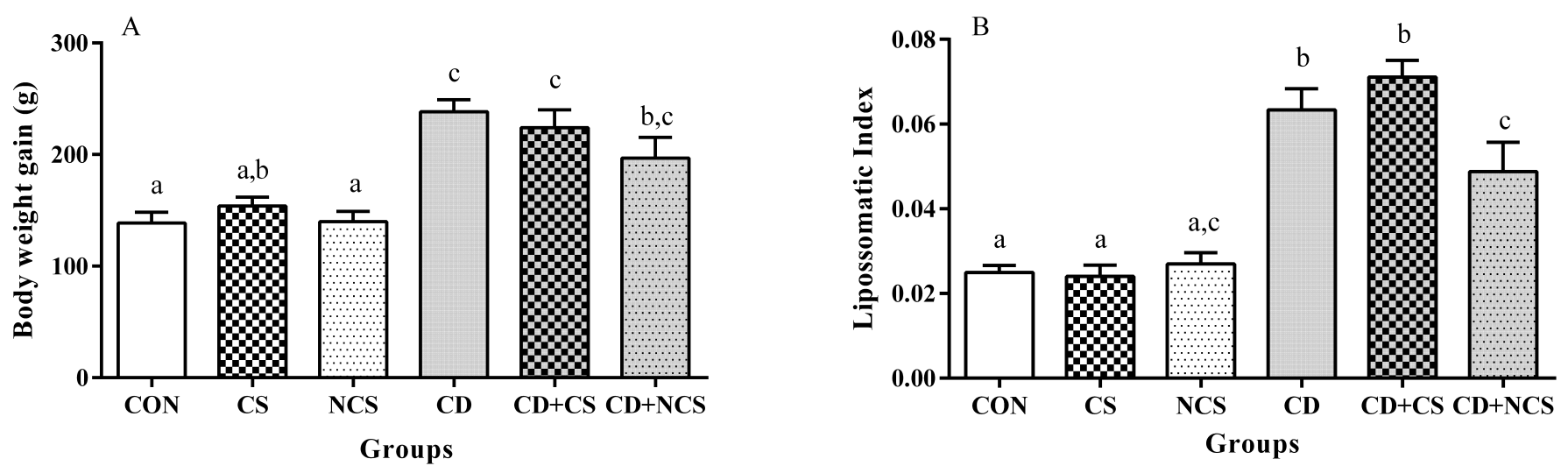

Figure 2

(A) Body Weight Gain (grams) and (B) Liposomatic index (LI= weight of intra-abdominal and perigonadal adipose tissue divided by body weight) at the end of the experiment (12th week). Data expressed as mean \pm SE of ten animals/group. CON (control); CS (caloric soft drink); NCS (non-caloric soft drink); CD (cafeteria diet); CD+CS $(C D+$ caloric soft drink); $C D+N C S$ (CD+non-caloric soft drink). a, b, c Different letters represent a significant difference ( $<0.05$; one way ANOVA with Tukey post hoc test) 